\title{
New Horizons!
}

Forgive me for starting off with some school teacher remarks! When editors and publishers write editorials and instructions for authors they generally mean what they say. Over the last 3 years the number of submissions to Respiration has steadily increased, which is fantastic. Many authors, however, do not seem to read our instructions very carefully. Let me point out the two most frequent mistakes, which will hopefully disappear after this editorial has appeared. First, abstracts of original investigations must have 5 subheadings: background, objectives, methods, results and conclusions; second, financial disclosure and conflict of interest must be divulged at the time of first submission of a manuscript. Further, as of 2001 all authors must sign the covering letter. Previously the first author's signature alone had been accepted on the bona fides that all co-authors had participated in the work and had agreed with the content of the submitted material. This time-honoured principal is unfortunately not acceptable for an international journal any longer.

But how is Respiration doing in the new millennium, you might want to know. Just fine, I tell you! Number and quality of submissions are up, and during the last 6 months we have been able to cut our acceptance rate to about $40 \%$ as planned. With the journal's continued quest for excellence, the acceptance rate for case reports, however, had to be cut even more to about $20 \%$. In order to avoid disappointment, case reports should only be submitted if they contain new and relevant information. (Yes, I have said that in my last editorial already, but the message has not been fully understood.)

Let me move to two exciting new topics and begin with the on-line Internet access of Respiration. So far it was possible to subscribe to the electronic version only in combination with the paper version. Subscribers had to pay a moderate fee in addition to the rate of the print version.
Online-only subscriptions were not available. This will change as of January 2001: For a one-year trial period, the publisher offers full-text online subscription to Respiration free of charge to all individuals who register at www.karger.com/respiration.htm. For the user this is the most attractive option, and I thank Karger Publishers for this offer. So far, the question has not been answered whether free full-text access leads to a decrease in subscription rates, or on the contrary may even increase subscriptions due to increased citations and subsequent positive effect on the impact factor. Let's watch and see!

Finally I take great pleasure in announcing the new section of 'Interventional Pulmonology' in the journal. By definition the term encompasses most bronchoscopic and thoracoscopic procedures of both diagnostic as well as therapeutic nature. It further includes techniques such as tracheostomies, mini-tracheostomies for the insertion of oxygen catheters, and transthoracic image-guided interventions. The advantage of this section is that it will appeal to pulmonologist, ENT- and thoracic surgeons as well as to interventional radiologists, who so far only published in their respective speciality journals. The section is unique and does not exist in any other European publication yet. The need for this entity of interventional pulmonology is real. To exemplify this suffice it to say that in the near future the European Association for Bronchology and Interventional Pulmonology (EAB) will be founded. One of the driving forces behind the scene is Professor H.D. Becker, Heidelberg, Germany, from whom the interested reader will be able to obtain hot on-line information at endoscopyhd@t-online.de.

Dear reader, Respiration is definitely off to new horizons, we hope you're with us to enjoy the ride!

C.T. Bolliger, Cape Town 